\title{
Spontaneous occult intracranial hypotension precipitating life-threatening cerebral venous thrombosis: case report
}

\author{
Avital Perry, MD, ${ }^{1}$ Christopher S. Graffeo, MD, ${ }^{1}$ Waleed Brinjikji, MD, ${ }^{2}$ William R. Copeland III, MD, ${ }^{3}$ \\ Alejandro A. Rabinstein, MD, ${ }^{4}$ and Michael J. Link, MD ${ }^{1,5}$ \\ Departments of ${ }^{1}$ Neurologic Surgery, ${ }^{2}$ Radiology-Diagnostic, ${ }^{4}$ Neurology, and ${ }^{5}$ Otolaryngology-Head and Neck Surgery, Mayo \\ Clinic, Rochester, Minnesota; and 'Division of Neurosurgery, Department of Surgery, Tenwek Hospital, Bomet, Kenya
}

\begin{abstract}
Spontaneous intracranial hypotension $(\mathrm{SIH})$ is an uncommon headache etiology, typically attributable to an unprovoked occult spinal CSF leak. Although frequently benign, serious complications may occur, including cerebral venous thrombosis (CVT). The objective of this study was to examine a highly complicated case of CVT attributable to SIH as a lens for understanding the heterogeneous literature on this rare complication, and to provide useful, evidence-based, preliminary clinical recommendations. A 43-year-old man presented with 1 week of headache, dizziness, and nausea, which precipitously evolved to hemiplegia. CT venography confirmed CVT, and therapeutic heparin was initiated. He suffered a generalized seizure due to left parietal hemorrhage, which subsequently expanded. He developed signs of mass effect and herniation, heparin was discontinued, and he was taken to the operating room for clot evacuation and external ventricular drain placement. Intraoperatively, the dura was deflated, suggesting underlying SIH. Ventral T-1 CSF leak was identified, which failed multiple epidural blood patches and required primary repair. The patient ultimately made a complete recovery. Systematic review identified 29 publications describing 36 cases of SIH-associated CVT. Among 31 patients for whom long-term neurological outcome was reported, $25(81 \%)$ recovered completely. Underlying coagulopathy/risk factors were identified in 11 patients (31\%). CVT is a rare and potentially lethal sequela occurring in $2 \%$ of SIH cases. Awareness of the condition is poor, risking morbid complications. Evaluation and treatment should be directed toward identification and treatment of occult CSF leaks. Encouragingly, good neurological outcomes can be achieved through vigilant multidisciplinary neurosurgical and neurocritical care.
\end{abstract}

https://thejns.org/doi/abs/10.3171/2017.10.SPINE17806

KEYWORDS cerebral venous thrombosis; cerebrospinal fluid leak; spontaneous intracranial hypotension; epidural blood patch; neurocritical care

$\mathrm{S}$ PONTANEOUS intracranial hypotension (SIH) is an uncommon headache etiology, typically attributable to an unprovoked CSF leak. $28,29,39,40$ More than $80 \%$ of patients present with orthostatic headache, yet a wide swath of symptoms has been reported, ranging from cervical pain, meningismus, nausea/vomiting, and imbalance, to rare symptoms including gait disturbance, auditory or visual changes, Parkinsonism, ataxia, dementia, paralysis, radiculopathy, and cranial nerve deficits. 4,29,39,42

Diagnosis of SIH is frequently delayed while treatment of more common headache etiologies is attempted. ${ }^{39}$ For most patients with $\mathrm{SIH}$, this results in prolonged discomfort, but minimal clinical impact, as complications are rare, and the condition ultimately responds well to treatment via epidural blood patch (EBP). ${ }^{29}$ However, severe complications of SIH have been reported, including cere- bral venous thrombosis (CVT). ${ }^{12,21,22,25,42,43}$ Although estimated to occur in just $2 \%$ of SIH cases, CVT may quickly precipitate life-threatening complications including intracranial hemorrhage, seizures, brain herniation, venous infarction, and raised intracranial pressure. ${ }^{42}$ We report a complex and challenging case of CVT due to SIH arising from a spontaneous CSF leak at the cervicothoracic junction (CTJ), from which the patient ultimately made a complete neurological recovery; in parallel, we review the pertinent literature regarding this rare and dangerous entity.

\section{Case Selection and Literature Review Methodology}

We reviewed the chart of a patient who underwent treatment for complex SIH with CVT for case reporting.

ABBREVIATIONS CTJ = cervicothoracic junction; CVT = cerebral venous thrombosis; EBP = epidural blood patch; EVD = external ventricular drain; SDH = subdural hematoma; $\mathrm{SIH}=$ spontaneous intracranial hypotension.

SUBMITTED July 18, 2017. ACCEPTED October 10, 2017.

INCLUDE WHEN CITING Published online March 30, 2018; DOI: 10.3171/2017.10.SPINE17806. 
Systematic review of the literature was initiated using PubMed, MEDLINE, Embase, and Google Scholar. Keywords and MeSH terms included "intracranial hypotension," "cerebral venous thrombosis," "venous sinus thrombosis," and "CSF" or "cerebros*" together with "leak," "hypotension," or "hypovolemia." Initial results after eliminating duplicates and performing bibliographic screening yielded 218 unique English-language publications. All cases or series describing clinically confirmed CVT attributable to SIH, with clear diagnostic evidence derived from radiographic, surgical, or therapeutic data, were included. Abstracts were screened independently by two authors (C.S.G. and W.R.C.) with instances of disagreement resolved by secondary review from the lead author (A.P.). Cumulatively, 29 articles describing 36 cases of CVT attributable to SIH were identified.

Included publications were reviewed in detail. Where available, individual patient characteristics and outcomes were captured, including: age; sex; presenting symptoms; evidence of SIH and/or CVT on initial imaging; treatments, including anticoagulation, EBP, surgical repair of CSF leak, or surgical treatment of an intracranial complication; resolution of symptoms (defined as complete vs incomplete return to presymptomatic baseline); complications; and findings on coagulopathy workup. STROBE guidelines were used as appropriate. Applicable components of this study were approved by our institutional IRB, which included an approved waiver of consent for minimal risk.

\section{Case Report}

History and Presentation

A 43-year-old man in excellent health presented to the emergency department complaining of new, intermittent, holocephalic non-orthostatic headaches, accompanied by dizziness and nausea, worsening over 1 week. The head CT scan was read as negative, neurology was not consulted, and the patient was referred to his primary care provider for a headache workup. Migraines were suspected, and sumitriptan and meclizine were initiated, with no relief. Subsequent outpatient MRI of the brain demonstrated smooth, diffuse dural and leptomeningeal enhancement, without tonsillar herniation or "brain sag" (Fig. 1A). The patient was referred to neurology, but while awaiting evaluation he experienced a severe headache and right-sided weakness, prompting a return to the emergency department.

Noncontrast head CT and CT venography demonstrated a large thrombus within the superior sagittal sinus overlying the frontal and parietal lobes, with extension into multiple bilateral cortical veins and no evidence of hemorrhage (Fig. 1B and C). Intravenous heparin was initiated with a bolus dose, and the patient was admitted to the neurosciences intensive care unit.

Three hours later, the patient experienced a generalized tonic-clonic seizure that self-limited after 45 seconds; lacosamide was administered using a loading dose, and emergency head CT demonstrated a $3.1 \times 3.8 \times 3.1-\mathrm{cm}$ left posterior parietal hemorrhage overlying a thrombosed cortical vein (Fig. 1D). The patient became somnolent and developed right gaze preference with right arm and leg paresis. As per American Heart Association/American Stroke Association guidelines, he was continued on intravenous heparin (last activated partial thromboplastin time prior to hemorrhage $=157$ seconds, first after hemorrhage = 99 seconds). ${ }^{35}$ Mannitol was initiated with marked improvement in his level of consciousness. Digital subtraction angiography demonstrated near-normal filling of the venous system, with evidence of contrast extravasation suggested by the presence of an "angiographic spot sign" (Fig. 1E). Twenty-four hours later, the patient developed recurrent somnolence and right hemiplegia; head CT demonstrated hemorrhage expansion (Fig. 1F). Heparin was discontinued, mannitol was increased, and $75 \mathrm{ml}$ of $10 \%$ sodium chloride was initiated intravenously, resulting in restoration of the patient's pre-expansion neurological examination.

Hypertonic saline was weaned successfully; however, 4 days later the patient became acutely somnolent with bilateral extensor posturing and a dilated, sluggish right pupil. He was emergently intubated and administered $100 \mathrm{ml}$ of $23.4 \%$ sodium chloride intravenously, which immediately restored his level of consciousness.

\section{Operation and Postoperative Course}

Repeat angiography showed venous pooling and decreased right transverse sinus flow suggesting mass effect, for which the patient was taken to the operating room for a stereotactic left parietal craniotomy, clot evacuation, and external ventricular drain (EVD) placement (Fig. 1G and $\mathrm{H}$ ). Evidence of CSF hypotension was immediately apparent following elevation of the craniotomy flap and direct exploration of the intracranial contents, as the dura appeared markedly deflated, without the expected turgor and with significant sag of the entire intradural contents. Samples of the hemorrhage were sent for pathologic analysis and confirmed to be negative for evidence of underlying tumor or vascular malformation.

Postoperatively, the patient was maintained in a $5^{\circ}$ Trendelenburg position (i.e., supine with head declined relative to the feet) with the EVD threshold at $15 \mathrm{~mm} \mathrm{Hg}$. Hyperosmolar therapy was continued, but intracranial pressure remained low and EVD output was minimal. Once the patient was medically stable while tolerating flat positioning, the EVD was removed and the patient was taken for MRI of the cervical spine, which demonstrated a large T2 hyperintense epidural fluid collection, indicating a ventral CSF leak (Fig. 2A and B). A CT-guided myelogram confirmed pronounced contrast extravasation at T1-2 adjacent to a calcified osteophyte, which diagnosed a high-flow CSF leak (Fig. 2C-F). This was treated via a triple injection EBP in the prone Trendelenburg position, with $10 \mathrm{ml}$ of autologous blood followed by 1-2 ml of fibrin glue infused into the bilateral T1-2 foramina, and an additional $10 \mathrm{ml}$ of blood injected into the T1-2 dorsal epidural space (Fig. 3). Approximate target volumes for injection were derived from the standardized $30 \mathrm{ml}$ thoracolumbar injection frequently used for occult-source SIH, adjusted for the difference in relative spinal canal and neuronal volumes between the high thoracic and thoracolumbar regions. ${ }^{30}$ 

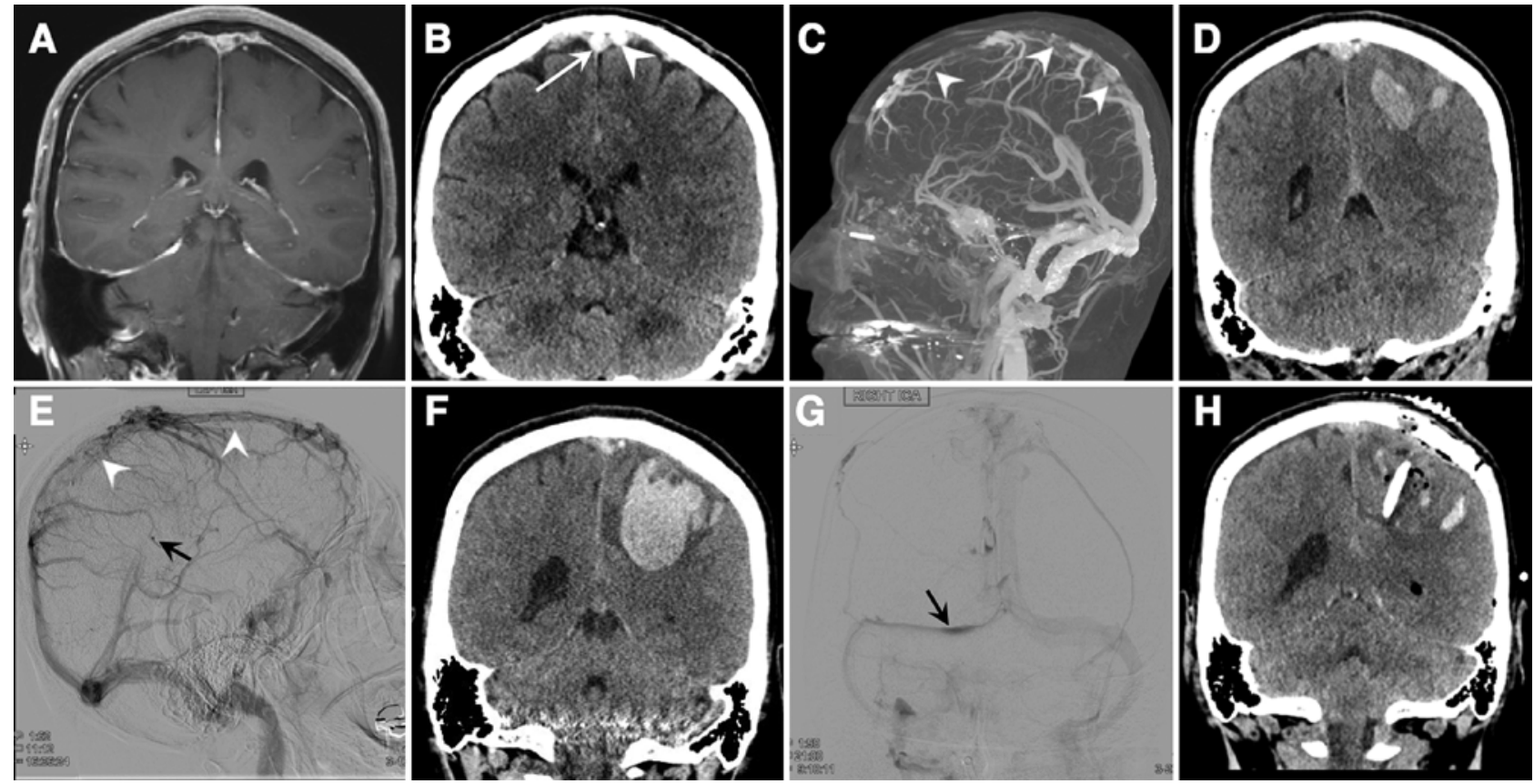

FIG. 1. A: Coronal T1-weighted contrast-enhanced MR image demonstrates diffuse smooth dural enhancement. B and C: Coronal noncontrast head CT image (B) demonstrates high attenuation in the superior sagittal sinus (arrow) as well as in an inflowing cortical vein (arrowhead), consistent with dural venous sinus thrombosis. This was subsequently confirmed via a 3D reformatted CT venogram (C), which demonstrated multiple superior sagittal sinus filling defects (arrowheads). D: Noncontrast head CT performed several hours later shows an acute left parietal intraparenchymal hematoma with associated effacement of the overlying sulci. E: Left internal carotid artery angiogram in the venous phase again demonstrates multiple superior sagittal sinus filling defects (arrowheads), as well as a pinpoint focus of contrast pooling in the region of the hematoma, consistent with an angiographic spot sign (arrow). F: Head CT acquired the next day shows expansion of the left parietal hematoma with increased vasogenic edema and mass effect. G: Repeat cerebral angiography with right internal carotid artery injection shows venous pooling and delayed contrast egress from the right transverse sinus (arrow), likely attributable to increased mass effect from the hematoma. $\mathrm{H}$ : Noncontrast head CT shows new postoperative changes of left parietal craniotomy for hematoma evacuation and EVD placement in the left lateral ventricle.

Flat positioning was maintained for 24 hours after EBP placement, followed by 48 hours of gradual elevation of the head of the bed to maximize fluid re-accumulation and promote scarring at the durotomy site. The patient's right-sided weakness and aphasia improved, although he reported a new horizontal diplopia that worsened on forced right gaze, suggesting incomplete right abducens palsy. He progressively recovered neurological function and was transferred to acute inpatient rehabilitation for residual right paresis.

Two weeks later, severe postural headaches recurred, and cervical imaging confirmed persistent high-flow CSF leak at T1-2, which was re-treated via epidural injection in the prone Trendelenburg position; after $4 \mathrm{ml}$ was injected, the patient reported severe back pain and paresthesias, and the procedure was aborted. After the procedure, the positional headaches had resolved; however, at the 3-month follow-up, although neurological function had returned to near baseline, intermittent moderate postural headaches had returned. In consideration of the fact that the patient had two failed attempts at treatment via EBP (the second of which was poorly tolerated) and had an obvious underlying structural lesion causing the recurrences, it was decided to eschew a third EBP and proceed directly to open repair. Correspondingly, he was returned to the operating room for a T1-2 laminectomy and intradural exploration, with exposure of the anterior elements via bilateral division of the T1-2 dentate ligaments. A persistent ventral durotomy was identified and repaired primarily using 6-0 permanent synthetic monofilament suture in a figure-ofeight fashion. The patient recovered uneventfully from this operation, and at last follow-up 6 months later reported definitive resolution of all headaches. Coagulopathy workup was nondiagnostic; although anticardiolipin immunoglobulin $\mathrm{G}$ antibodies were noted to be weakly positive on two discrete tests, both were significantly below the diagnostic threshold for antiphospholipid syndrome.

\section{Literature Review}

Twenty-nine publications describing 36 cases of CVT attributable to SIH were identified and reviewed in detail (Table 1). Mean and median ages were 41 years (range 2975 years; Table 2), with a slight male predominance (54\%). Postural headache was the most common presentation (83\%), followed by nausea/vomiting (28\%) and nonpostural headache $(14 \%)$. Less prevalent symptoms including sensory changes $(11 \%)$, auditory disturbance $(11 \%)$, seizure (8\%), disequilibrium (8\%), altered mental status (8\%), visual disturbance (3\%), and plegia/paresis (3\%). MRI 

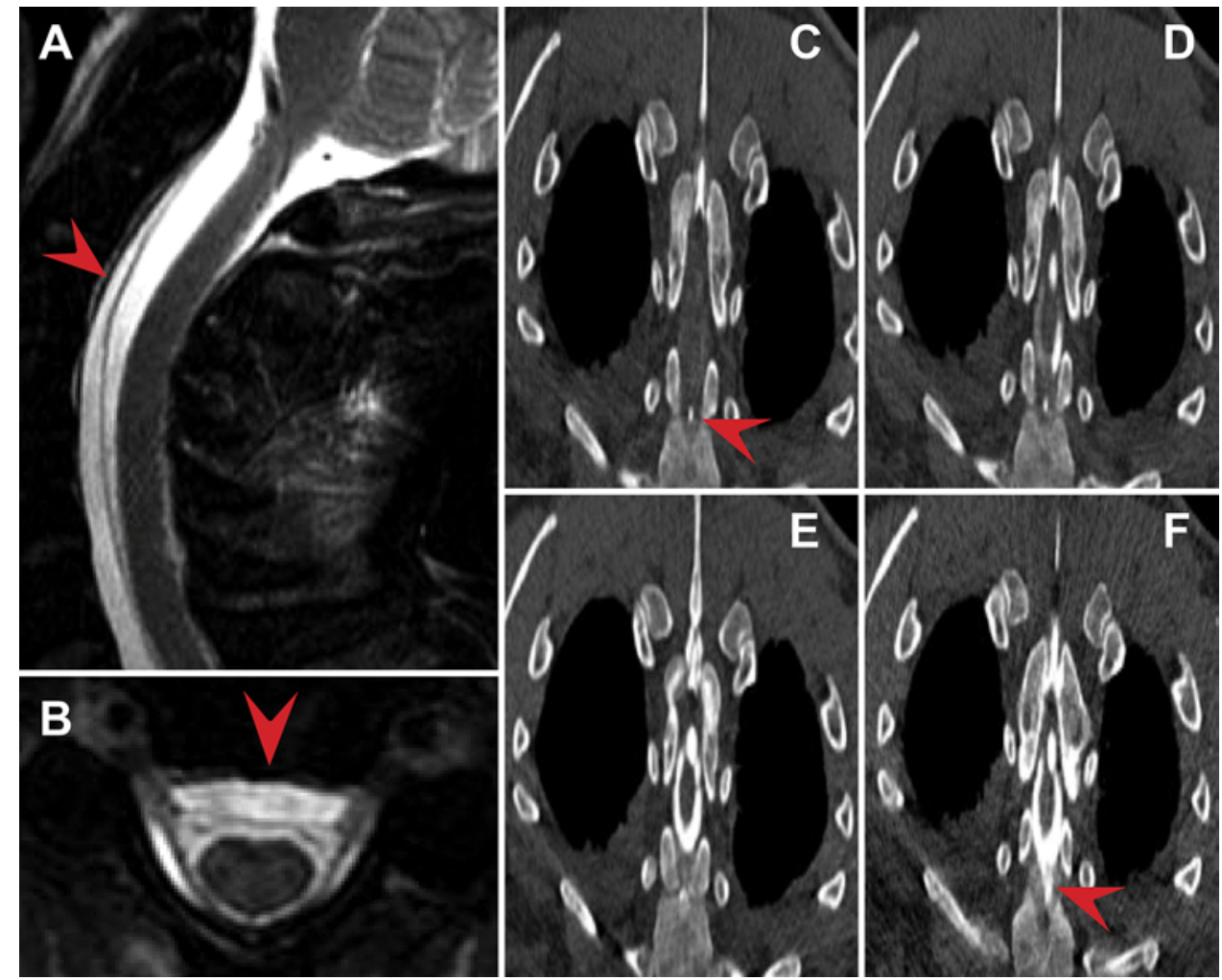

FIG. 2. A and B: Sagittal (A) and axial (B) T2-weighted MR images of the cervical spine demonstrate an expansive, CSF-isodense, ventral epidural fluid collection (arrowhead), extending from C1-2 inferiorly to beyond the CTJ. C-F: Obliquely angled, dynamic CT myelography without contrast identifies a calcified ventral osteophyte $(\mathrm{C}$, arrowhead), adjacent to which frank extravasation of a large volume of contrast is observed in a time-dependent fashion (D-F, arrowhead). Figure is available in color online only.

studies of the brain at presentation contained evidence of $\mathrm{SIH}$ in 35 patients (97\%) and CVT in $31(86 \%)$, many of which were not initially recognized. Spinal imaging was performed in 13 patients $(36 \%)$, all of which identified a CSF leak; among these, $46 \%$ were localized to the CTJ (defined as C7-T1), 39\% to the thoracic spine, and $15 \%$ to the cervical spine.
CVT was treated with anticoagulation in 32 patients (89\%). CSF leak was treated via EBP in 15 patients (42\%), and open repair in $2(6 \%)$. Three patients $(8 \%)$ required cranial surgery for treatment of a CVT complication such as subdural hematoma (SDH). One death was reported (3\%); major nonfatal complications included intraparenchymal hemorrhage in $8(22 \%)$, seizure in $8(22 \%), \mathrm{SDH}$
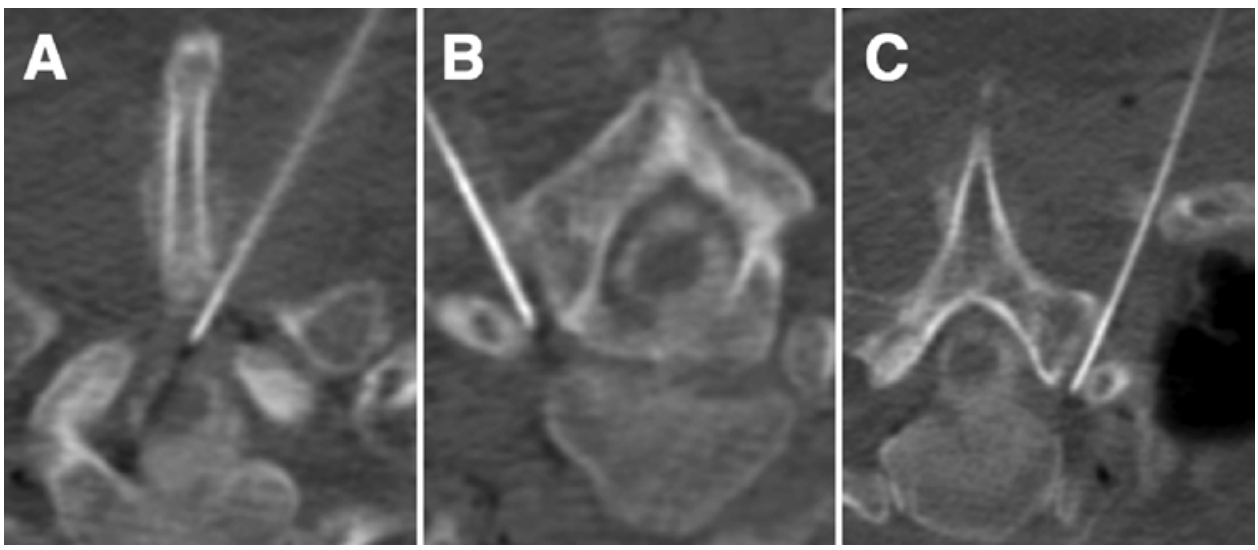

FIG. 3. CT fluoroscopic images from the EBP injection demonstrate three 20-gauge Tuohy needles, inserted into the dorsal epidural fat of T1-2 (A), and the perineural foraminal fat surrounding the bilateral exiting T-1 nerve roots (B and C). Ten milliliters of autologous blood was infused into each transforaminal needle, followed by $1-2 \mathrm{ml}$ of fibrin glue; an additional $10 \mathrm{ml}$ of blood was subsequently injected into the T1-2 dorsal epidural space. 


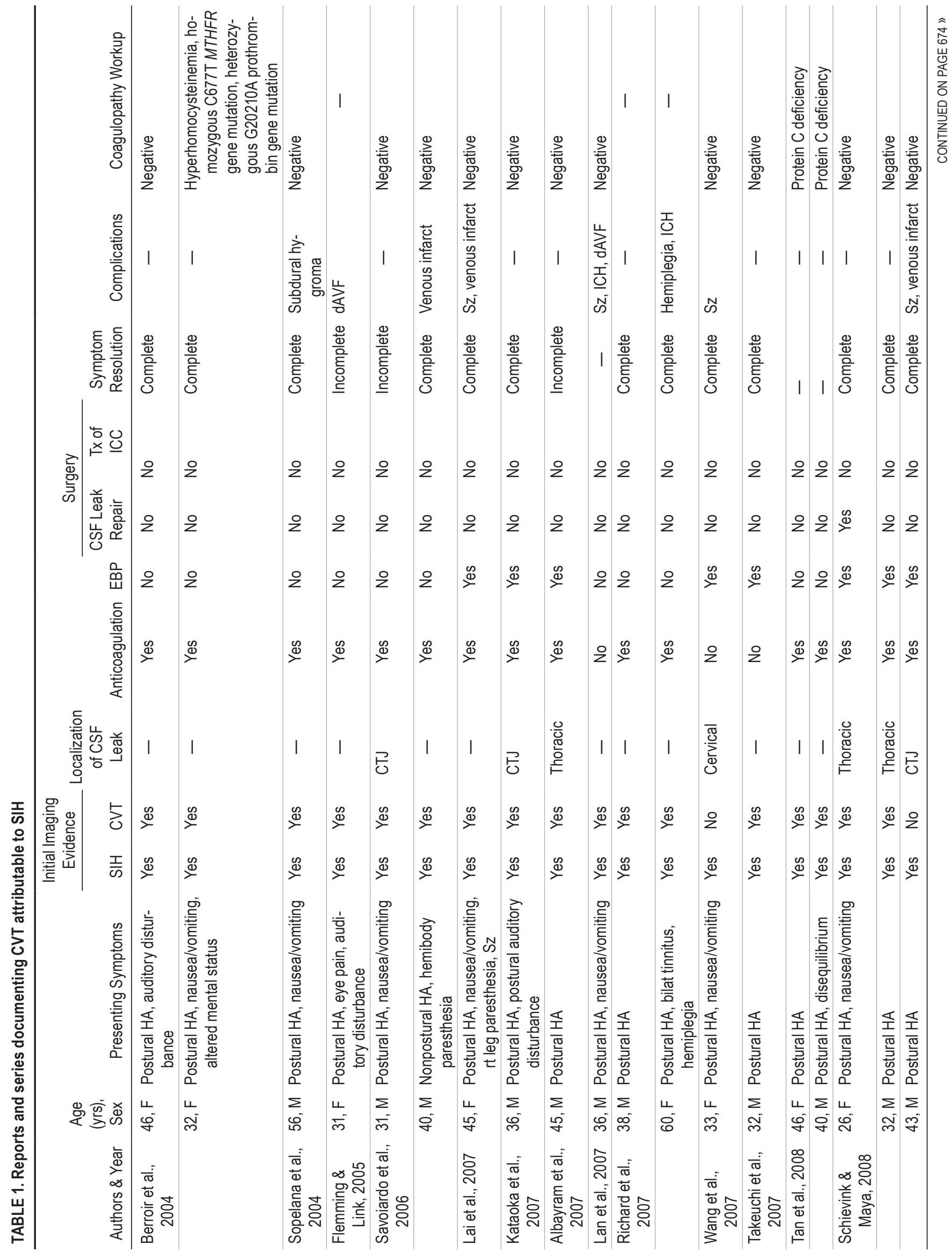




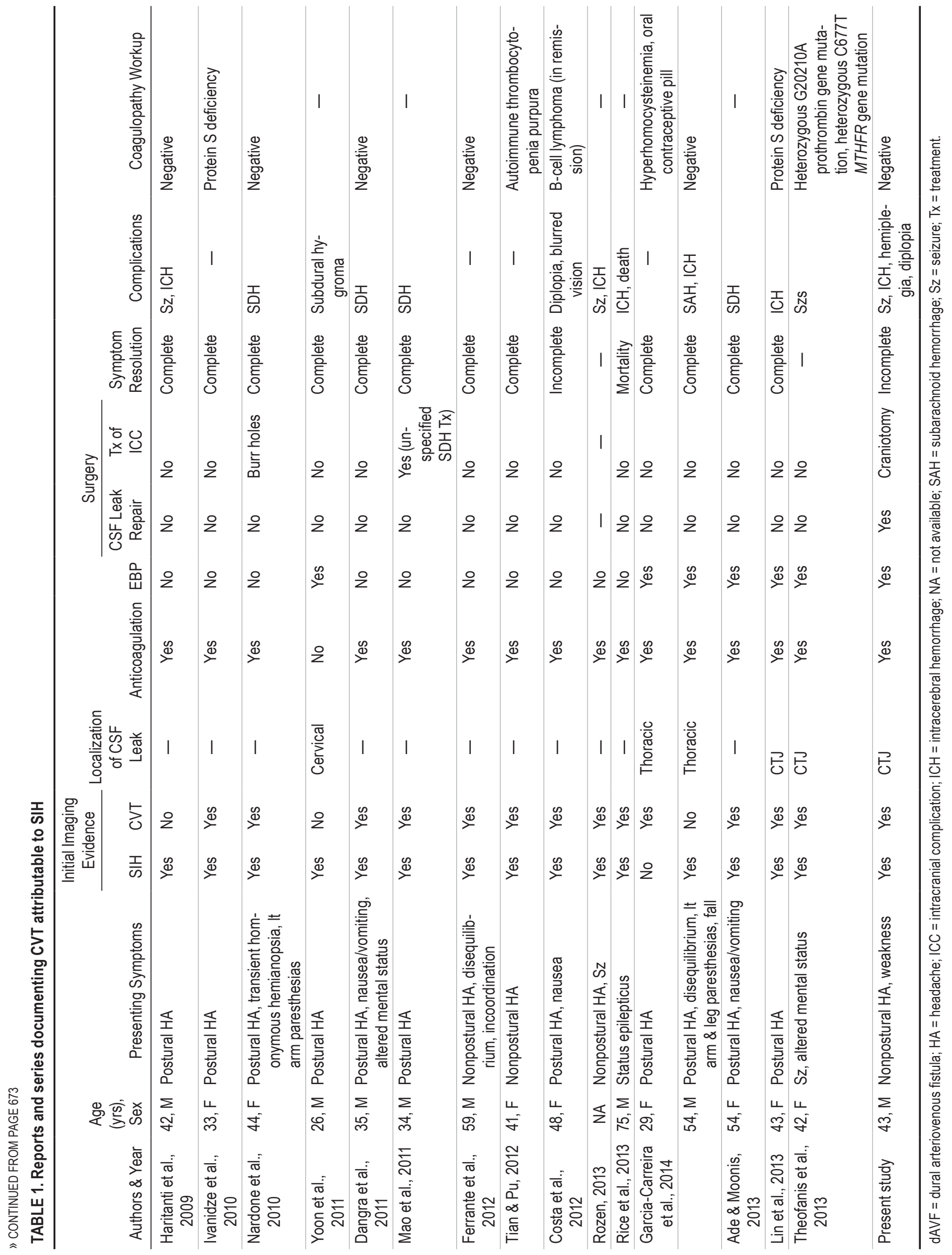


in $4(11 \%)$, nonhemorrhagic venous infarct in $3(8 \%)$, subdural hygroma in $2(6 \%)$, dural arteriovenous fistula in 2 $(6 \%)$, visual deficit in $2(6 \%)$, and nonaneurysmal nontraumatic subarachnoid hemorrhage in 1 patient $(3 \%)$.

Coagulopathy workup was completed in 28 patients (76\%), of which 19 (68\%) were negative. Positive risk factors or major complex coagulopathies included deficiencies of protein $\mathrm{C}$ or protein $\mathrm{S}$ in $2(7 \%)$ each, hyperhomocysteinemia in $2(7 \%)$, gene mutations in $M T H F R$ or prothrombin in $2(7 \%)$ each, and current oral contraceptive use or a history of B-cell lymphoma in $1(4 \%)$ each.

\section{Discussion}

Although typically benign, SIH may precipitate lethal complications, including CVT and its sequelae. The occurrence of this rare condition is unpredictable and demonstrates a highly variable natural history, with outcomes ranging from complete resolution to severe disability or death. Our case and accompanying literature review-the first specifically surveying CVT in the setting of SIHhighlight the significant challenges inherent to managing complicated SIH.

Diagnosis presents the first and most important hurdle in SIH-associated CVT, as both are frequently misdiagnosed..$^{38,42}$ Orthostatic headache should immediately raise suspicion, as should MRI abnormalities including leptomeningeal enhancement, pituitary hyperemia, flattening of the optic chiasm, anterior displacement of the pons against the clivus, or acquired Chiari malformation. ${ }^{39,40} \mathrm{~A}$ change in headache pattern heralds CVT in $40 \%$ of cases, but a high index of suspicion is warranted in any SIH patient with neurological changes, as delayed diagnosis or treatment is associated with worse outcomes. . $^{2,18,27,35,42}$

The pathophysiology linking SIH to CVT is incompletely understood, and likely multifactorial. Schievink and Maya propose three major coincident mechanisms linking changes in flow dynamics between the CSF and venous compartments to thrombosis. ${ }^{42}$ First, as dictated by the Monro-Kellie doctrine, the loss of CSF results in a necessary expansion of the venous compartment, and the resultant venous engorgement slows flow through these vessels. This possibility is further supported by ultrasound-based studies that have demonstrated a decrease in flow through the straight sinus following CSF diversion via lumbar puncture. ${ }^{6}$ Simultaneously, the redirection of CSF through the durotomy into the epidural space, rather than into the venous system, causes an increase in dural venous blood viscosity. Finally, the downward sagging of intracranial structures puts traction on the thin-walled veins and sinuses, and this mechanical distortion leads to turbulence or stasis.

These concepts inform our treatment paradigm for CVT in SIH. Our patient responded dramatically to repositioning, including prolonged Trendelenburg with an EVD in place. This maneuver likely alleviated the impact of brain sag on venous anatomy, and decreased the rate of CSF egress through the thoracic durotomy. That the patient improved following administration of hyperosmolar therapy in the setting of intracranial hypotension seems counterintuitive at first glance; however, the effect of increased circulating osmoles is to mobilize more fluid

TABLE 2. Summary statistics of CVT attributable to SIH

\begin{tabular}{|c|c|}
\hline Variable & Value \\
\hline \multicolumn{2}{|l|}{ Demographics } \\
\hline Median age, yrs & 41 \\
\hline Mean age (range), yrs & $41(29-75)$ \\
\hline Women, no. $(\%)^{*}$ & $16(46)$ \\
\hline Men, no. $(\%)^{*}$ & $19(54)$ \\
\hline \multicolumn{2}{|l|}{ Presenting symptoms, no. (\%) } \\
\hline Postural HA & $30(83)$ \\
\hline Nausea/vomiting & $10(28)$ \\
\hline Nonpostural HA & $5(14)$ \\
\hline Sensory changes & $4(11)$ \\
\hline Auditory disturbance & $4(11)$ \\
\hline $\mathrm{Sz}$ & $3(8)$ \\
\hline Disequilibrium & $3(8)$ \\
\hline Altered mental status & $3(8)$ \\
\hline Visual disturbance & $1(3)$ \\
\hline Plegia/paresis & $1(3)$ \\
\hline \multicolumn{2}{|l|}{ Treatment, no. (\%) } \\
\hline Anticoagulation & $32(89)$ \\
\hline EBP & $15(42)$ \\
\hline Operative repair of CSF leak & $2(6)$ \\
\hline Operative treatment of ICC & $3(8)$ \\
\hline \multicolumn{2}{|l|}{ Brain imaging, no. (\%) } \\
\hline SIH on presenting MRI & $35(97)$ \\
\hline CVT on presenting MRI & $31(86)$ \\
\hline CVT on subsequent imaging & $36(100)$ \\
\hline \multicolumn{2}{|l|}{ Spinal imaging, no. $(\%) \dagger$} \\
\hline CTJ CSF leak & $6(46)$ \\
\hline Thoracic CSF leak & $5(39)$ \\
\hline Cervical CSF leak & $2(15)$ \\
\hline \multicolumn{2}{|l|}{ Complications, no. $(\%)$} \\
\hline Intraparenchymal hemorrhage & $8(22)$ \\
\hline Sz & $8(22)$ \\
\hline $\mathrm{SDH}$ & $4(11)$ \\
\hline Venous infarct & $3(8)$ \\
\hline Subdural hygroma & $2(6)$ \\
\hline dAVF & $2(6)$ \\
\hline Visual deficit & $2(6)$ \\
\hline SAH & $1(3)$ \\
\hline Death & $1(3)$ \\
\hline \multicolumn{2}{|l|}{ Coagulopathy workup, no. (\%)‡ } \\
\hline Negative workup & $19(68)$ \\
\hline Protein $\mathrm{C}$ deficiency & $2(7)$ \\
\hline Protein S deficiency & $2(7)$ \\
\hline Hyperhomocysteinemia & $2(7)$ \\
\hline MTHFR gene mutation & $2(7)$ \\
\hline Prothrombin gene mutation & $2(7)$ \\
\hline Oral contraceptive pill & $1(4)$ \\
\hline B-cell lymphoma & $1(4)$ \\
\hline \multicolumn{2}{|l|}{ Neurological outcome, no. (\%)§ } \\
\hline Complete recovery & $25(81)$ \\
\hline Incomplete recovery & $5(16)$ \\
\hline Death & $1(3)$ \\
\hline $\begin{array}{l}\text { *ne study did not report the sex of the pat } \\
\dagger n=13 . \\
\ddagger n=28 . \\
\S n=31 .\end{array}$ & \\
\hline
\end{tabular}


first into the venous compartment and then quickly out of the intracranial space, simultaneously reducing venous volume and stasis. A simultaneous decrease in parenchymal edema likely mitigated the effects of brain herniation. Interestingly, Stephen et al. approached treating SIH pathophysiology from a different direction, and infused intrathecal saline in a patient with SIH complicated by $\mathrm{SDH} .{ }^{49}$ Their patient improved significantly following the intervention, providing further proof of concept that normalization of the venous-CSF system is a central tenet in managing complicated $\mathrm{SIH}$, although definitive treatment requires repair of the underlying leak.

This observation invites the question of how an EBP should be timed in the context of therapeutic anticoagulation for CVT. Clinical guidelines for the management of CVT of any cause are based on two small, randomized trials incorporating 79 patients, and a Cochrane review and meta-analysis of the same data. ${ }^{8,10,11,35}$ Although the authors ultimately conclude that anticoagulation is safe, potentially prevents thrombus propagation, and may facilitate recanalization, there is no unequivocal evidence mandating early implementation. In our review, 32 of 36 patients received anticoagulation; of the 32, 20 did not undergo EBP, 13 of whom made complete neurological recovery, comparable to 9 recoveries in 12 treated with anticoagulation and EBP (65\% vs 75\%). Three patients with CVT underwent EBP without preceding anticoagulation, all of whom made a complete recovery, suggesting that EBP may warrant consideration as first-line therapy.

This strategy finds further support in other reports that demonstrated persistent thrombus or SDH during the anticoagulation period, with subsequent resolution after EBP. ${ }^{2,20}$ The potential benefits of an EBP-first paradigm are underscored by the fact that active therapeutic anticoagulation prohibits EBP, and reversal of anticoagulation may be a risk factor for propagation of residual clot. ${ }^{23,45}$ An EBP-first framework would require a well-resourced clinical environment, early diagnosis of SIH-associated CVT, and a stable patient; more frequently, early imaging is limited to head CT/CT venography, and reflex initiation of anticoagulation is recommended over delayed care, particularly in critical cases.

Defining the optimal role for more aggressive interventions beyond EBP in the treatment of complicated SIH presents an even more ambiguous challenge. Clearly, the need for operative management is best decided on a caseby-case basis, governed by hemorrhage severity or refractoriness of CSF leak to EBP. Studies focused on uncomplicated SIH have suggested that EBP should be attempted at least 3 times before moving to open repair, and even then, surgery is generally advocated only in the presence of a definitive radiographic source..$^{41,44,46}$ In the absence of a localized durotomy, large volume ( $\geq 30 \mathrm{ml}$ ) lumbar or thoracolumbar infusion is preferred for safety reasons, but given the predominance of cervicothoracic leaks, multiple treatments are often required. However, in the setting of an unambiguous lesion and a competent neurointerventionalist, we recommend targeted therapy, which has been successfully reported as proximal as C-2. ${ }^{31}$

The final key concept in managing SIH-associated CVT is avoidance of secondary complications via optimizing neurointensive care, with recommendations derived from the broader literature on CVT of any etiology. Seizures are the most common CVT sequelae; previously reported to occur in $37 \%$ of adult cases, our literature review identified seizures in $8(53 \%)$ of the 15 patients in whom complications were reported in detail. ${ }^{3}$ Treatment with antiepileptic medications is recommended after a single seizure, as is $\mathrm{CT}$ of the head to rule out hemorrhage, the most common precipitating factor. ${ }^{26,35}$ In parallel, dehydration is believed to contribute to both the initiation and propagation of CVT, and maintenance of normovolemia or moderate hypervolemia is recommended. ${ }^{14,37,48}$ This is particularly relevant in patients receiving hyperosmolar therapy, who are often in critical condition, and at highest risk for dehydration that may trigger a precipitous decline.

Our study is limited in several ways due to the restrictions of the available data. Both our case and the literature review are retrospective and collectively identified only 36 patients. Previously reported outcomes are heterogeneously and incompletely described, preventing formal statistical analysis, a particularly problematic issue with respect to complications and outcomes. However, in spite of these shortcomings, the present study marks the first systematic review focused on CVT as a complication of SIH, and a small but essential step forward in our understanding of this challenging and complex clinical entity.

\section{Conclusions}

CVT is a rare complication of SIH, which is itself a frequently undiagnosed cause of headache. CVT has the potential to precipitate devastating neurological consequences, and requires nuanced management that simultaneously targets the underlying cause while providing supportive neurointensive care. Further study aimed at optimizing an algorithm for early treatment of these patients is requisite, with a particular focus on the timing of EBP and anticoagulation. Perhaps even more importantly, physician education regarding SIH must be improved, as the condition is widely underdiagnosed, placing patients at risk for avoidable complications including CVT, dural arteriovenous fistula, intracranial hemorrhage, and a range of other potentially devastating injuries. Although CVT may result in significant morbidity and mortality, excellent recovery is possible even among critically ill patients through aggressive management by the neurosurgical and neurocritical care teams.

\section{References}

1. Ade S, Moonis M: Intracranial hypotension with multiple complications: an unusual case report. Case Rep Neurol Med 2013:913465, 2013

2. Albayram S, Tasmali KM, Gunduz A: Can spontaneous intracranial hypotension cause venous sinus thrombosis? J Headache Pain 8:200-201, 2007

3. Ameri A, Bousser MG: Cerebral venous thrombosis. Neurol Clin 10:87-111, 1992

4. Bassani L, Graffeo CS, Behrooz N, Tyagi V, Wilson T, Penaranda S, et al: Noninvasive diagnosis and management of spontaneous intracranial hypotension in patients with Marfan syndrome: case report and review of the literature. Surg Neurol Int 5:8, 2014 
5. Berroir S, Grabli D, Héran F, Bakouche P, Bousser MG: Cerebral sinus venous thrombosis in two patients with spontaneous intracranial hypotension. Cerebrovasc Dis 17:9-12, 2004

6. Canhão P, Batista P, Falcão F: Lumbar puncture and dural sinus thrombosis - a causal or casual association? Cerebrovasc Dis 19:53-56, 2005

7. Costa P, Del Zotto E, Giossi A, Volonghi I, Poli L, Frigerio $\mathrm{M}$, et al: Headache due to spontaneous intracranial hypotension and subsequent cerebral vein thrombosis. Headache 52:1592-1596, 2012

8. Coutinho JM, de Bruijn SF, deVeber G, Stam J: Anticoagulation for cerebral venous sinus thrombosis. Stroke 43: $41-$ e42, 2012

9. Dangra VR, Sharma YB, Bharucha NE, Deopujari CE: An interesting case of headache. Ann Indian Acad Neurol 14:130-132, 2011

10. de Bruijn SF, Stam J: Randomized, placebo-controlled trial of anticoagulant treatment with low-molecular-weight heparin for cerebral sinus thrombosis. Stroke 30:484-488, 1999

11. Einhäupl KM, Villringer A, Meister W, Mehraein S, Garner C, Pellkofer M, et al: Heparin treatment in sinus venous thrombosis. Lancet 338:597-600, 1991

12. Fabricius J, Klotz JM, Hofmann E, Behr R, Neumann-Haefelin T: [Cerebral venous thrombosis and subdural haematoma: complications of spontaneous intracranial hypotension.] Fortschr Neurol Psychiatr 80:599-601, 2012 (Ger)

13. Ferrante T, Latte L, Abrignani G, Russo M, Manzoni GC, Torelli P: Cough headache secondary to spontaneous intracranial hypotension complicated by cerebral venous thrombosis. Neurol Sci 33:429-433, 2012

14. Ferro JM: Causes, predictors of death, and antithrombotic treatment in cerebral venous thrombosis. Clin Adv Hematol Oncol 4:732-733, 2006

15. Flemming KD, Link MJ: Spontaneous CSF leak complicated by venous thrombosis and dural arteriovenous fistula. Cephalalgia 25:751-753, 2005

16. Garcia-Carreira MC, Vergé DC, Branera J, Zauner M, Herrero JE, Tió E, et al: Cerebral venous thrombosis in two patients with spontaneous intracranial hypotension. Case Rep Neurol Med 2014:528268, 2014

17. Haritanti A, Karacostas D, Drevelengas A, Kanellopoulos V, Paraskevopoulou E, Lefkopoulos A, et al: Spontaneous intracranial hypotension: clinical and neuroimaging findings in six cases with literature review. Eur J Radiol 69:253-259, 2009

18. Idrissi AL, Lacour JC, Klein O, Schmitt E, Ducrocq X, Richard S: Spontaneous intracranial hypotension: characteristics of the serious form in a series of 24 patients. World Neurosurg 84:1613-1620, 2015

19. Ivanidze J, Zimmerman RD, Sanelli PC: Spontaneous intracranial hypotension followed by dural sinus thrombosis: a case report. Clin Neurol Neurosurg 112:498-500, 2010

20. Kataoka H, Tanizawa E, Ueno S: Spontaneous intracranial hypotension is associated with a risk of venous sinus thrombosis and subdural hematoma. Cerebrovasc Dis 23:315-317, 2007

21. Lai PH, Li JY, Lo YK, Wu MT, Liang HL, Chen CK: A case of spontaneous intracranial hypotension complicated by isolated cortical vein thrombosis and cerebral venous infarction. Cephalalgia 27:87-90, 2007

22. Lan MY, Chang YY, Liu JS: Delayed cerebral venous thrombosis in a patient with spontaneous intracranial hypotension. Cephalalgia 27:1176-1178, 2007

23. Leissinger CA, Blatt PM, Hoots WK, Ewenstein B: Role of prothrombin complex concentrates in reversing warfarin anticoagulation: a review of the literature. Am J Hematol 83:137-143, 2008

24. Lin CH, Chen YY, Hsieh YZ, Lo MC: Spontaneous intracranial hypotension complicated with cerebral venous thrombo- sis and intracerebral hemorrhage in a patient with protein $S$ deficiency: a case report. Changhua J Med 11:48-53, 2013

25. Mao YT, Dong Q, Fu JH: Delayed subdural hematoma and cerebral venous thrombosis in a patient with spontaneous intracranial hypotension. Neurol Sci 32:981-983, 2011

26. Masuhr F, Busch M, Amberger N, Ortwein H, Weih M, Neumann K, et al: Risk and predictors of early epileptic seizures in acute cerebral venous and sinus thrombosis. Eur J Neurol 13:852-856, 2006

27. Mea E, Chiapparini L, Savoiardo M, Franzini A, Bussone G, Leone M: Clinical features and outcomes in spontaneous intracranial hypotension: a survey of 90 consecutive patients. Neurol Sci 30 (Suppl 1):S11-S13, 2009

28. Mokri B: Spontaneous cerebrospinal fluid leaks: from intracranial hypotension to cerebrospinal fluid hypovolemia-evolution of a concept. Mayo Clin Proc 74:1113-1123, 1999

29. Mokri B: Spontaneous low pressure, low CSF volume headaches: spontaneous CSF leaks. Headache 53:1034-1053, 2013

30. Nardone R, Caleri F, Golaszewski S, Ladurner G, Tezzon F, Bailey A, et al: Subdural hematoma in a patient with spontaneous intracranial hypotension and cerebral venous thrombosis. Neurol Sci 31:669-672, 2010

31. Rai A, Rosen C, Carpenter J, Miele V: Epidural blood patch at C2: diagnosis and treatment of spontaneous intracranial hypotension. AJNR Am J Neuroradiol 26:2663-2666, 2005

32. Rice CM, Renowden SA, Sandeman DR, Cottrell DA: Spontaneous intracranial hypotension and venous sinus thrombosis. Pract Neurol 13:120-124, 2013

33. Richard S, Kremer S, Lacour JC, Vespignani H, Boyer P, Ducrocq X: Cerebral venous thrombosis caused by spontaneous intracranial hypotension: two cases. Eur J Neurol 14:12961298, 2007

34. Rozen TD: Pachymeningeal enhancement on MRI: a venous phenomena not always related to intracranial hypotension (resolving pachymeningeal enhancement and cerebral vein thrombosis). Headache 53:673-675, 2013

35. Saposnik G, Barinagarrementeria F, Brown RD Jr, Bushnell $\mathrm{CD}$, Cucchiara B, Cushman M, et al: Diagnosis and management of cerebral venous thrombosis: a statement for healthcare professionals from the American Heart Association/ American Stroke Association. Stroke 42:1158-1192, 2011

36. Savoiardo M, Armenise S, Spagnolo P, De Simone T, Mandelli ML, Marcone A, et al: Dural sinus thrombosis in spontaneous intracranial hypotension: Hypotheses on possible mechanisms. J Neurol 253:1197-1202, 2006

37. Sawarkar DP, Verma SK, Singh PK, Doddamani R, Kumar A, Sharma BS: Fatal superior sagittal sinus and torcular thrombosis after vestibular schwannoma surgery: report of a rare complication and review of the literature. World Neurosurg 96:607.e19-607.e24, 2016

38. Schievink WI: Misdiagnosis of spontaneous intracranial hypotension. Arch Neurol 60:1713-1718, 2003

39. Schievink WI: Spontaneous spinal cerebrospinal fluid leaks. Cephalalgia 28:1345-1356, 2008

40. Schievink WI: Spontaneous spinal cerebrospinal fluid leaks and intracranial hypotension. JAMA 295:2286-2296, 2006

41. Schievink WI: Spontaneous spinal cerebrospinal fluid leaks: a review. Neurosurg Focus 9(1):e8, 2000

42. Schievink WI, Maya MM: Cerebral venous thrombosis in spontaneous intracranial hypotension. Headache 48:15111519,2008

43. Schievink WI, Maya MM, Nuño M: Chronic cerebellar hemorrhage in spontaneous intracranial hypotension: association with ventral spinal cerebrospinal fluid leaks: clinical article. J Neurosurg Spine 15:433-440, 2011

44. Schievink WI, Morreale VM, Atkinson JL, Meyer FB, Piepgras DG, Ebersold MJ: Surgical treatment of spontaneous spinal cerebrospinal fluid leaks. J Neurosurg 88:243-246, 1998 
45. Schulman S, Bijsterveld NR: Anticoagulants and their reversal. Transfus Med Rev 21:37-48, 2007

46. Sencakova D, Mokri B, McClelland RL: The efficacy of epidural blood patch in spontaneous CSF leaks. Neurology 57:1921-1923, 2001

47. Sopelana D, Marcos A, Arroyo R, Gutiérrez E, Cuenca R, Vázquez AV, et al: May intracranial hypotension be a cause of venous sinus thrombosis? Eur Neurol 51:113-115, 2004

48. Stam J: Cerebral venous and sinus thrombosis: incidence and causes. Adv Neurol 92:225-232, 2003

49. Stephen CD, Rojas R, Lioutas VA, Papavassiliou E, Simon DK: Complicated spontaneous intracranial hypotension treated with intrathecal saline infusion. Pract Neurol 16:146-149, 2016

50. Takeuchi S, Takasoto Y, Masaoka H, Hayakawa T, Otani N, Yoshino Y, et al: Spontaneous intracranial hypotension associated with dural sinus thrombosis. Neurol Med Chir (Tokyo) 47:555-558, 2007

51. Tan K, Venketasubramanian N, Hwang CY, Lim CC: My headache does not get better when I lie down: spontaneous intracranial hypotension complicated by venous thrombosis. Headache 48:149-152, 2008

52. Theofanis B, El-Chalouhi M, Tjoumakaris M: Cerebrospinal fluid leakage and cerebral venous sinus thrombosis: a case report. JHN J 8:2, 2013

53. Tian CL, Pu CQ: Dural enhancement detected by magnetic resonance imaging reflecting the underlying causes of cerebral venous sinus thrombosis. Chin Med J (Engl) 125:15131516,2012
54. Wang YF, Fuh JL, Lirng JF, Chang FC, Wang SJ: Spontaneous intracranial hypotension with isolated cortical vein thrombosis and subarachnoid haemorrhage. Cephalalgia 27:1413-1417, 2007

55. Yoon KW, Cho MK, Kim YJ, Lee SK: Sinus thrombosis in a patient with intracranial hypotension: a suggested hypothesis of venous stasis. A case report. Interv Neuroradiol 17:248251,2011

\section{Disclosures}

The authors report no conflict of interest concerning the materials or methods used in this study or the findings specified in this paper.

\section{Author Contributions}

Conception and design: Link, Perry, Rabinstein. Acquisition of data: all authors. Analysis and interpretation of data: Link, Perry, Brinjikji, Copeland. Drafting the article: Perry, Brinjikji. Critically revising the article: all authors. Reviewed submitted version of manuscript: Link, Perry. Administrative/technical/material support: Perry. Study supervision: Link.

\section{Correspondence}

Michael J. Link: Mayo Clinic, Rochester, MN. link.michael@ mayo.edu. 